\title{
NEWS
}

\section{Dealer unearths Hooke's Royal Society notes}

The battered folio of notes looks like many others that have landed on the desk of Felix Pryor, manuscript expert at Bonhams auction house in London. But when he leafed through the pages of intricate seventeenth-century handwriting, Pryor quickly realized he was looking at the most exciting scientific documents he had ever handled: a set of original minutes and commentary that detail the birth of modern science. "My jaw hit the floor," he says.

The manuscripts are due to go on sale next month with an estimated value of $£ 1$ million (US $\$ 1.8$ million). They capture the early days of Britain's oldest research institution, the Royal Society, through the eyes of Robert Hooke - a brilliant physicist, chemist and mechanic who during his career engaged in well-documented rows with contemporaries such as Isaac Newton. Historians who have seen the papers say they settle a major controversy in the development of timekeeping and provide fascinating insights into the fledgling UK research body.

Most of the notes date from Hooke's tenure as secretary of the society between 1677 and 1682 , a time when Newton was developing his theory of gravity and Gottfried Leibniz was working on calculus. Transcriptions of Hooke's minutes, which record the group's weekly Thursday meetings, were printed at the time and survive to this day. But the discovery of the originals fills in several gaps created when the copies were made.

A second section sheds light on a 300-yearold quarrel over the invention of the springbalance watch, a major advance in timekeeping. The invention is often attributed to the Dutch physicist Christiaan Huygens, but Hooke always daimed that he had demonstrated the device at a Royal Society meeting in June 1670, five years before Huygens patented his. As the society's transcribed minutes make no mention of such a demonstration, many historians have questioned Hooke's claim.

The notes may change that thinking. The second section was written by Hooke as he looked

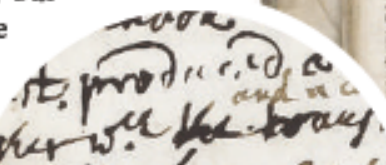
to hecen from gricfr pronigsto Delimer

Science historians are desperate for Hooke's notes to remain accessible to study.

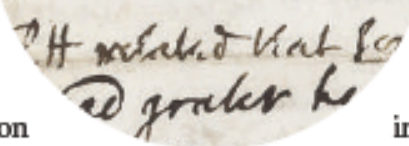

Other parts of the manuscript suggest that Hooke was indeed furious. Oldenburg's printed minutes for 1676 omit another of through original minutes handwritten by his predecessor as secretary, Henry Oldenburg. Hooke had removed a sheet of Oldenburg's minutes and placed it in his folio. It contains details of the pocket-watch experiment that Oldenburg never transcribed into the official records. "Hooke must have been incensed when he found it," says Lisa Jardine, a historian at Queen Mary, University of London, and a biographer of Hooke. Hooke's experiments, this time on magnetism. In his commentary, Hooke notes: ${ }^{\alpha}$ The dog has entred nothing but Left a blank."

The documents were found last September in a cupboard in a house in Hampshire, southern England, during a routine valuation of other items. The owners say they have no idea how they came by the manuscript, and that it had been in the cupboard for as long as they can remember.

\section{Drop in HIV infection rate used to justify focus on morality}

A study claiming good news on Africa's fight against AIDS has reignited conflicts over the effectiveness of HIV prevention campaigns, particularly the merits of focusing on abstinence and monogamy.

Researchers reported last week that HIV infection rates in Zimbabwe fell between 1998 and 2003 from $23 \%$ to $20.5 \%$ (S. Gregson et al. Science 311, 664-666; 2006). They claimed that the gains came thanks to behavioural changes by Zimbabweans, who were having sex at a later age and with fewer partners. Women also reported more frequent condom use.

Some scientists and government officials hailed the finding as showing that campaigns persuading people to change their behaviour can succeed. "This supports the idea that

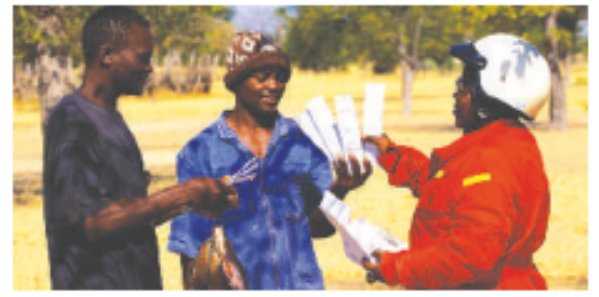

Greater condom use and monogamy are being linked to a fall in HIV in Zimbabwe.

behavioural change has resulted in a reduction in new infections in this study population," says Richard Hayes, an epidemiologist at the London School of Hygiene and Tropical Medicine.

More controversially, US officials claim that the study validates their foreign policy. A third of US money spent on AIDS prevention overseas goes on programmes promoting abstinence 8 and being faithful to one partner - the ' $\mathrm{A}$ ' and ' $\mathrm{B}$ ' in the 'ABC model', where ' $\mathrm{C}$ ' stands for condoms. Critics say that focus is based on morality, not science, and can be unrealistic, especially for women who may have no choice about with whom they or their partners sleep.

Deputy US global AIDS coordinator Mark Dybul says the Zimbabwe study and earlier gains in Uganda help to put such criticisms to rest. ${ }^{\alpha}$ The greatest behaviour change was in abstinence and fidelity, he points out.

But Simon Gregson of Imperial College London, who led the Zimbabwe study, insists that "we need to be promoting all the different prevention possibilities". 


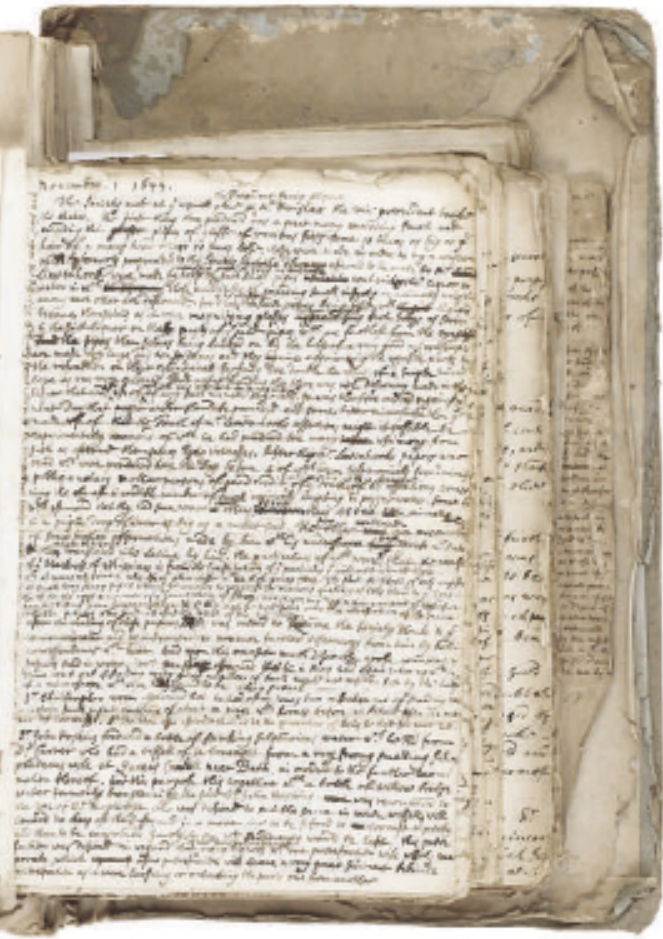

Jardine and others say it is vital that the manuscript remains accessible after its sale, so that it can be properly studied by science historians. But there is no guarantee that will happen. The Royal Society says it wants to bid for the documents, but lacks the funds. "I believe there is a lot of other serious stuff in there," says Jardine. "I'm desperate that it goes to an accessible home."

Should a foreign collector triumph in the auction, the UK government is likely to impose a three-month delay on issuing an export licence for the manuscript. Such a move would be designed to enable British museums to raise funds to mount a rival bid; UK law dictates that a museum could take possession if it matched the winning bid. Jim Giles

And some warn that other factors have been overlooked. Maria Wawer of Columbia University in New York, co-leader of a long-running study in Uganda, thinks deaths from AIDS play a role. Although prevention programmes deserve some credit, she says, "there's no reason to believe mortality is not contributing to this". After a decline in the late 1990s, HIV prevalence in Uganda now seems to be levelling off or even climbing back up.

The drop in Zimbabwe could also have been affected by violence and unrest, which have escalated there since 2000. Epidemiologist Christopher Beyrer of Johns Hopkins University in Baltimore, Maryland, says forced relocations and the departure of millions of young people seeking work may have skewed the study's results. ErikaCheck

\section{Possible planets left with no name}

Astronomers trying to define a 'planet' won't announce a decision until August at the earliest, and may duck the issue entirely. In the meantime, researchers are left unable to name some newly discovered objects.

The issue was raised when astronomers led by the California Institute of Technology's Mike Brown reported finding objects that came close to Pluto in size, including Quaoar in 2002 and Sedna in 2004. It came to a head in July 2005, when the group announced the discovery of an even larger object, temporarily dubbed $2003 \mathrm{UB}_{313}$. Last week, scientists confirmed that this is substantially bigger than Pluto (F. Bertoldi et al. Nature 439, 563-564; 2006).

Until astronomers decide what counts as a planet, $\mathrm{UB}_{313}$ cannot be officially named. The International Astronomical Union (IAU) catalogues such objects, but different committees are responsible for naming major planets, and mere chunks of rock or ice. The indecision "really interferes with our work", says Brian Marsden, head of the Minor Planets Centre in Cambridge, Massachusetts, which catalogues thousands of objects every year.

Brown's discoveries, 2005

FY9 and 2003 EL61, are also waiting to be named.

The IAU set up a 19-strong committee in 2004 to resolve the issue, which reported to the executive committee in November. Some experts suggested that anything spherical that orbits the kilometres across should be called a planet. That size limit would indude Pluto and $\mathrm{UB}_{313}$, and was selected as "arbitrary but sensible", according to Iwan Williams, president of IAU's planetarysystems sciences division.

But other suggestions included stripping Pluto of its title, because thousands of objects occupy the same area of space, known as the Kuiper belt. "We should speak of eight major planets," says Marsden. "People say schoolchildren will be upset, but so what? It's our job to educate them." Sun and is more than 2,000
Others disagree. "Pluto is obviously a planet," says Alan Stern of the Southwest Research Institute in Boulder, Colorado, who heads the New Horizons mission that has just set off to Pluto. He argues that anything big enough to form a sphere as it orbits a star should be called a planet including the asteroid Ceres. This list could be broken down into categories such as 'terrestrial planet' or 'gas giant' (see Nature 437, 456-457; 2005).

The matter is now likely to be referred to the entire IAU membership at a meeting in Prague this August. Robert Williams, who sits on the executive committee, isn't optimistic about a resolution: "Nineteen experts wrestled with this for six months and didn't reach a conclusion." He favours waiting until more is known about the edges of our Solar System, and the planets around other stars. "My recommendation is we're not ready to move on this yet."

Mark Peplow

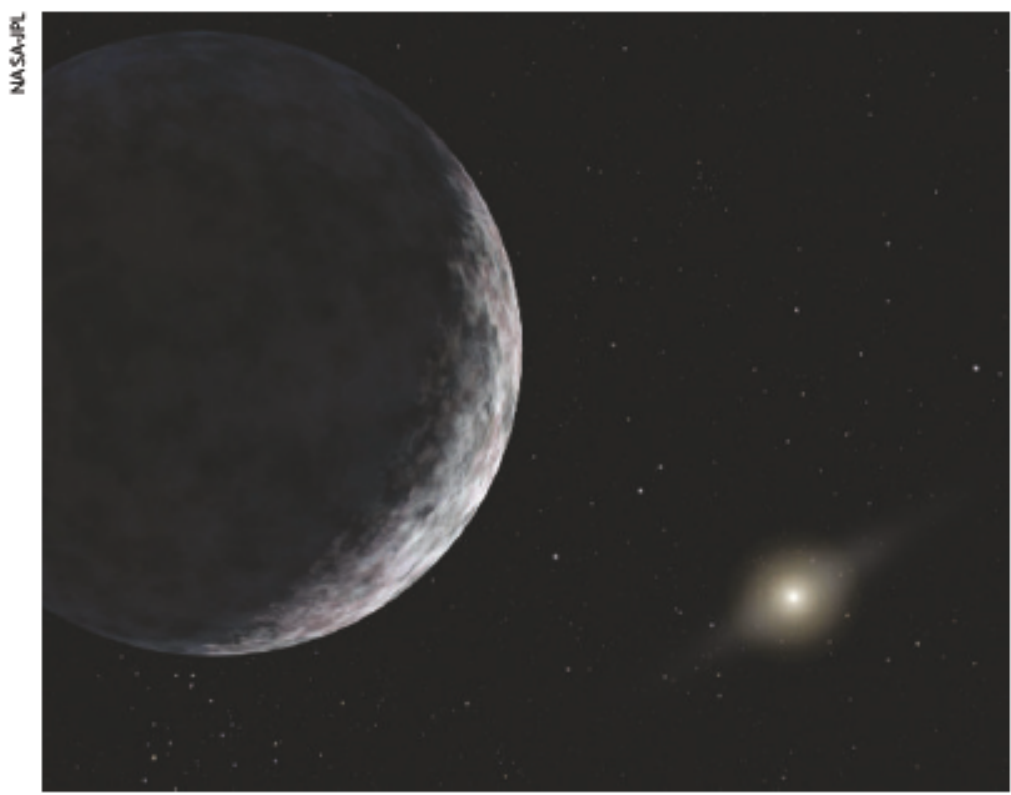

New arrival: $\mathrm{UB}_{38}$ is bigger thanPluto but hasn't yetbeen formally named because of indecision about itsstatus. 